\title{
Conduction velocity in the peripheral nerves of rats with chronic carbon disulphide neuropathy
}

\author{
K. KNOBLOCH ${ }^{1}$, J. STETKIEWICZ ${ }^{2}$, AND T. WROŃSKA-NOFER ${ }^{3}$ \\ From the ${ }^{1}$ Departments of Toxicology, ${ }^{2}$ Pathomorphology and ${ }^{3}$ Biochemistry, Institute of Occupational \\ Medicine, 90-950 Lódź, Teresy 8, Poland
}

\begin{abstract}
Effects of carbon disulphide $\left(\mathrm{CS}_{2}\right)$ on conduction velocity in sciatic and tibial nerve were investigated in rats exposed to $\mathrm{CS}_{2}$ vapour at concentrations of $0.9 \mathrm{mg} / \mathrm{l}$ or $1.6 \mathrm{mg} / \mathrm{l}$ of air for periods of $1 \cdot 5,3,6,9$ and 12 months. The conduction velocity was measured on the day following each exposure period, and again, three and six months after the last day of exposure. The majority of exposed rats showed a reduction in conduction velocity on the day after exposure: the extent of this reduction was dependent on the $\mathrm{CS}_{2}$ concentration and the duration of exposure. Exposure for 1.5 months to $1.6 \mathrm{mg} \mathrm{CS} / 1$ produced temporary and fully reversible impairment of conduction velocity. Increased exposure to $\mathrm{CS}_{2}\left(3,6\right.$ or 9 months at $1.6 \mathrm{mg} / \mathrm{l} ; 6$ or 12 months at $0.9 \mathrm{mg} / \mathrm{CS}_{2}$ in air) caused a reduction in velocity which was only partially reversible.
\end{abstract}

Peripheral neuropathy caused by carbon disulphide $\left(\mathrm{CS}_{2}\right)$ poisoning has been recognised since the second half of the nineteenth century. It has been observed in workers of the viscose rayon industry and induced experimentally in animals exposed to $\mathbf{C S}_{2}$. Measurement of conduction velocity in peripheral nerves has recently aroused interest as a sensitive electrophysiological method for detecting early functional changes in the peripheral nerves both of men and of animals exposed to $\mathrm{CS}_{2}$ (Lukas, 1969; Lukas, 1970; Lukas et al., 1974; Seppalainen and Tolonen, 1974; Linnoila et al., 1975; Vasilescu, 1976).

The aim of the study dzscribed here was to determine the changes in conduction velocity in the sciatic and tibial nerves of rats exposed to $\mathrm{CS}_{\mathbf{2}}$ at concentrations of $0.9 \mathrm{mg} / \mathrm{l}$ air and $1.6 \mathrm{mg} / \mathrm{l}$ air, and the dynamics of recovery after exposure had end $\mathrm{d}$.

\section{Methods}

One hundred and forty-three white female Wistar rats, initially three months old, were used. They were exposed to $\mathrm{CS}_{2}$ vapour at concentrations of $0.9 \mathrm{mg} / 1$

Received for publication 13 March 1978

Accepted for publication 24 July 1978
$(0.8-1.0 \mathrm{mg} / \mathrm{l})$ or $1.6 \mathrm{mg} / \mathrm{l}(1.5-1.7 \mathrm{mg} / \mathrm{l})$ in an inhalation chamber five hours daily, six days a week in separate groups for $1 \cdot 5,3,6,9$ or 12 months. Both exposed and control rats were given a standard diet and water ad libitum.

Conduction velocity was measured the day after the end of any exposure period, and again three and six months later.

Measurements were performed on animals anaesthetised i.p. with $0.3 \mathrm{~g}$ chloral hydrate/ $\mathrm{kg}$ body weight; the animals were kept warm by means of a lamp heater while the measurements were being taken. The anal and hind limb skin temperature during that time remained constant in control and $\mathrm{CS}_{2}$-exposed rats $\left( \pm 1^{\circ} \mathrm{C}\right)$.

The method used was a modification of that described by Fullerton and Barnes (1966). The sciatic and tibial nerves were stimulated at points $\mathbf{S}_{1}$ and $S_{2}$ (Fig. 1) with supramaximal stimuli (250-300 V) for $50 \mu \mathrm{s}$. The stimulating cathode was a stainless steel needle inserted through the skin into a paracentral region of the thigh, close to the sciatic nerve $\left(\mathrm{S}_{1}\right)$ and into the medial side of the ankle close to the posterior tibial nerve $\left(\mathbf{S}_{2}\right)$. The action potential from the interosseous and lumbrical muscles on the plantar side of the hind paw was picked up by a concentric needle electrode and recorded on a Hewlett-Packard 


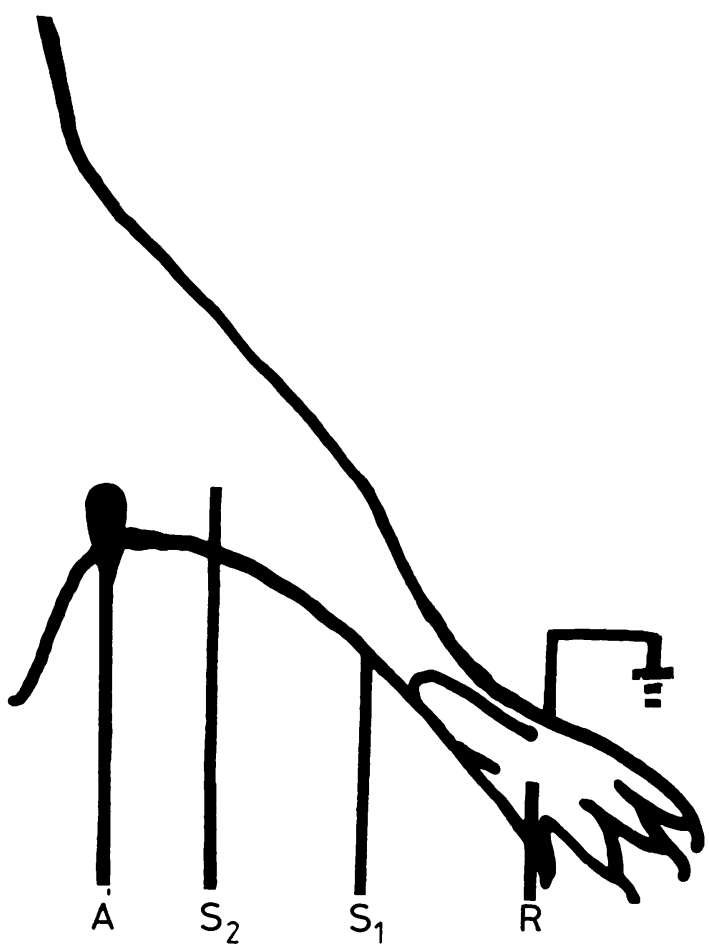

Fig. 1 Arrangement of electrodes. $A=$ anode; $S_{1}$ and $S_{2}=$ cathodes; $R=$ recording electrode.

electromyograph oscilloscope. The conduction velocity was calculated by dividing the distance between points of stimulation $S_{1}$ and $S_{2}$ by the difference between the two latencies recorded on the oscilloscope (Figs. 2 and 3).

\section{Results}

Obvious general symptoms of $\mathrm{CS}_{2}$ intoxication, such as loss of body weight, staggering and muscle weakness developed between the fourth and sixth months of exposure to $1.6 \mathrm{mg} \mathrm{CS} 2 / 1$ of air; however, rats exposed to a lower concentration of $\mathrm{CS}_{2}(0.9 \mathrm{mg} / \mathrm{l})$ remained healthy throughout the entire experimental period.

Electrophysiological changes preceded the general symptoms of intoxication. The amount by which conduction velocity was reduced in the sciatic and tibial nerve was dependent on the level and duration of $\mathrm{CS}_{2}$ exposuie and on the length of the recovery period. A reduction attributable to $\mathrm{CS}_{2}$ at a concentration of $1.6 \mathrm{mg} / \mathrm{l}$ was noticeable after 1.5 months' exposure. Longer exposure periods exacerbated the electrophysiological changes, recorded the day after exposure ended (Table 1).

Conduction velocity did not differ significantly from control values, within three months of 1.5 months' exposure to $1.6 \mathrm{mg} \mathrm{CS} / \mathrm{l}$. After rats had been exposed for three months to this level of $\mathrm{CS}_{2}$ vapour, the conduction velocities were found to be similar, after a three- and a six-month recovery period, to those found in rats exposed for only 1.5 months (Table 1, Fig. 4). The conduction velocity was found also to revert to near-normal values when six months' exposure was followed by three- and sixmonth recovery periods. During the first three months after a nine-month exposure to $1.6 \mathrm{mg}$ $\mathrm{CS}_{2}$, impairment of conduction velocity actually increased, and minor improvement was delayed until six months after exposure had ended.

A statistically significant reduction in conduction velocity was also found in rats exposed to $0.9 \mathrm{mg}$ $\mathrm{CS}_{2}$ /litre air for six or for 12 months, but was less marked than that seen in rats exposed to the higher concentration of $\mathrm{CS}_{2}$. It was most obvious after 12 months' of $\mathrm{CS}_{2}$ exposure (Table 2). Three months after exposure had endcd a further decrease was noted in conduction velocity in this group of animals, and after a total of six months' recovery, only a slight improvement in conduction velocity was found (Table 2, Fig. 5).

\section{Discussion}

The results of this study show that decrease in the conduction velocity is related to the concentration of $\mathrm{CS}_{2}$ inhaled and to the duration of exposure. A similar conclusion was drawn by Lukas (1970) from his study on rats exposed for six and nine months to $\mathrm{CS}_{2}$ at concentrations of $\mathbf{1 . 2}$ and $2.4 \mathrm{mg} / \mathrm{l}$. Linnoila et al. (1975) and Lukas (1970) have also found a partial improvement in conduction velocity in rabbits and rats three months after the end of exposure to $2.4 \mathrm{mg} / \mathrm{kg} \mathrm{CS} / \mathrm{l}$. Our observations showed that the improvement in conduction velocity after exposure is also dependent on the level and duration of $\mathbf{C S}_{2}$ exposure.

It is of particular interest that the conduction velocity actually deteriorated over the first three months after long-term exposure to $\mathbf{C S}_{2}$ had ended (Figs. 4 and 5). Some improvement could be seen eventually, six months after the end of exposure, but, even then the conduction velocity remained slower than that in control animals of the same age.

Morphological aspects of $\mathbf{C S}_{2}$ neuropathy were discussed in our previous publications (Szendzikowski et al., 1973, 1974). The basic lesion of the peripheral nervous system, attributable to $\mathrm{CS}_{2}$, affects the 


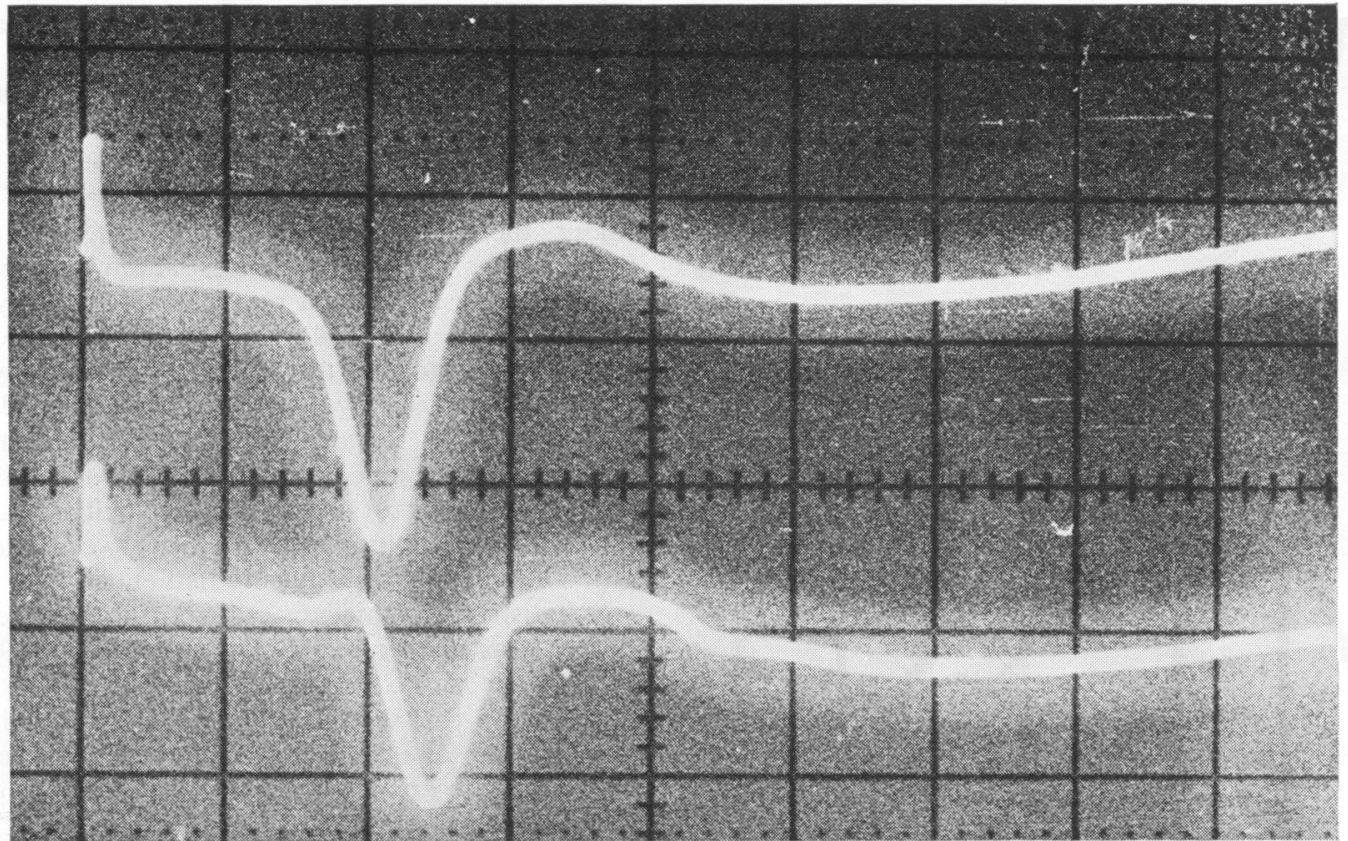

Fig. 2 Muscle action potentials induced by nerve stimulation at two different points in control rat. Distance between long vertical lines $=2 \mathrm{mV}$. Latency difference $=0.4 \mathrm{~m} / \mathrm{s}$. Distance $S_{2}-S_{1}$ in the hind limb of the rat $=20 \mathrm{~mm}$. Conduction velocity $=50 \mathrm{~m} / \mathrm{s}$.

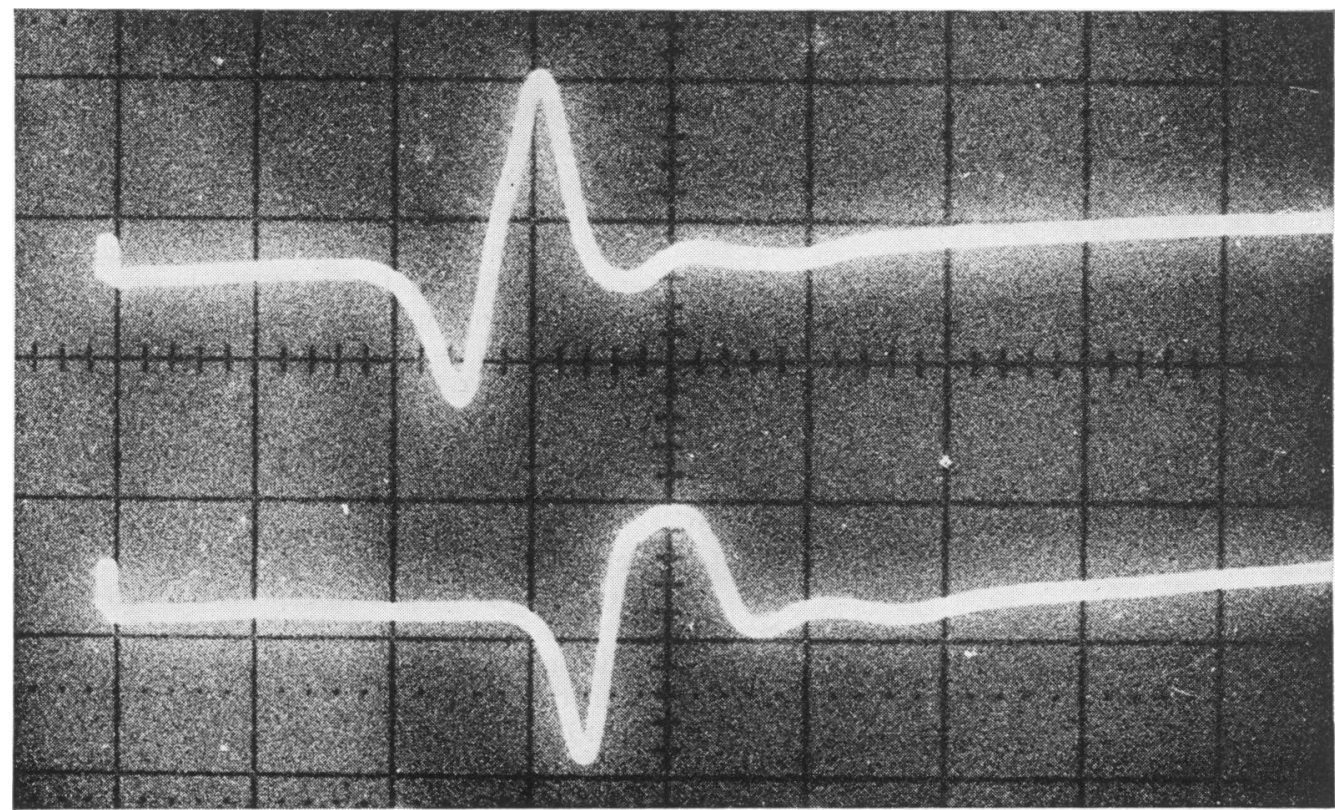

Fig. 3 Muscle action potentials induced by nerve stimulation in a rat exposed to $1.6 \mathrm{mg} / \mathrm{l} \mathrm{CS}$ for six months. Distance $S_{2}-S_{1}$ in the hind limb of the rat $=22 \mathrm{~mm}$. Latency difference $=1 \mathrm{~m} / \mathrm{s}$. Conduction velocity $=22 \mathrm{~m} / \mathrm{s}$. 
Table 1 Conduction velocity in the sciatic and tibial nerves of rats exposed to $1.6 \mathrm{mg} \mathrm{CS} / \mathrm{l}$ air

\begin{tabular}{|c|c|c|c|c|c|c|}
\hline \multirow{3}{*}{$\begin{array}{l}\text { Duration of } \\
\text { (exposure) } \\
\text { (months) }\end{array}$} & \multicolumn{6}{|c|}{ Conduction velocity $\dagger$ in the sciatic and tibial nerves at various times after end of exposure } \\
\hline & \multicolumn{2}{|l|}{24 hours } & \multicolumn{2}{|l|}{3 months } & \multicolumn{2}{|l|}{6 months } \\
\hline & Control & $C S_{2}$ & Control & $C S_{2}$ & Control & $C S_{2}$ \\
\hline 1.5 & $54 \cdot 4 \underset{(9)}{ \pm} 7 \cdot 2$ & $\begin{array}{c}42 \cdot 9 \pm 4 \cdot 1 * * * \\
(10)\end{array}$ & $\begin{array}{c}45 \cdot 6 \pm 3 \cdot 9 \\
(10)\end{array}$ & $41 \cdot 3 \underset{(9)}{ \pm} 5 \cdot 2$ & - & - \\
\hline 3 & $\begin{array}{c}45 \cdot 6 \pm 2 \cdot 5 \\
(10)\end{array}$ & $\begin{array}{c}32 \cdot 2 \pm 8 \cdot 0^{* * * *} \\
(14)\end{array}$ & $\begin{array}{c}43 \cdot 1 \pm 4 \cdot 8 \\
(8)\end{array}$ & $\begin{array}{c}34 \cdot 6 \pm 3 \cdot 7^{ \pm * *} \\
(8)\end{array}$ & 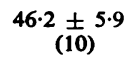 & $39 \cdot 2 \pm 4 \cdot{ }_{(8)}^{*}$ \\
\hline 6 & $\begin{array}{c}54 \cdot 6 \pm 6 \cdot 2 \\
(6)\end{array}$ & $\begin{array}{c}25 \cdot 1 \underset{(9)}{ \pm} 4 \cdot 2^{* * *} \\
\text { (1) }\end{array}$ & $\begin{array}{c}46 \cdot 3 \underset{(8)}{ \pm} 5 \cdot 0 \\
\text { (8) }\end{array}$ & $\begin{array}{c}38.5 \underset{(5)}{ \pm} 1.9 * * \\
\end{array}$ & $\begin{array}{c}45 \cdot 5 \pm 6 \cdot 0 \\
(8)\end{array}$ & $37 \cdot 4 \underset{(5)}{ \pm}$ \\
\hline 9 & $\begin{array}{c}46.9 \pm \\
(8)\end{array}$ & $\begin{array}{c}20 \cdot 3 \pm 4 \cdot 5^{* * * *} \\
(18)\end{array}$ & $\begin{array}{c}44 \cdot 1 \underset{(6)}{ \pm} 6 \cdot 9 \\
\text { (6) }\end{array}$ & $\begin{array}{l}16.7 \underset{(7)}{ \pm} 1.9 * * * \\
(7)\end{array}$ & $\begin{array}{c}49 \cdot 2 \pm 5 \cdot 0 \\
(13)\end{array}$ & $\begin{array}{c}34 \cdot 3 \underset{(8)}{ \pm} \\
7 \cdot 5^{* * * *}\end{array}$ \\
\hline
\end{tabular}

$\dagger$ Results expressed in metres/second as average \pm standard deviation. Figures in parentheses represent number of animals used in the experiment. Statistically significant differences from the control group:

$+0.01<P<0.05$

$* * ; 0.001<P<0.01$

$* * * ; \quad P 0.001$

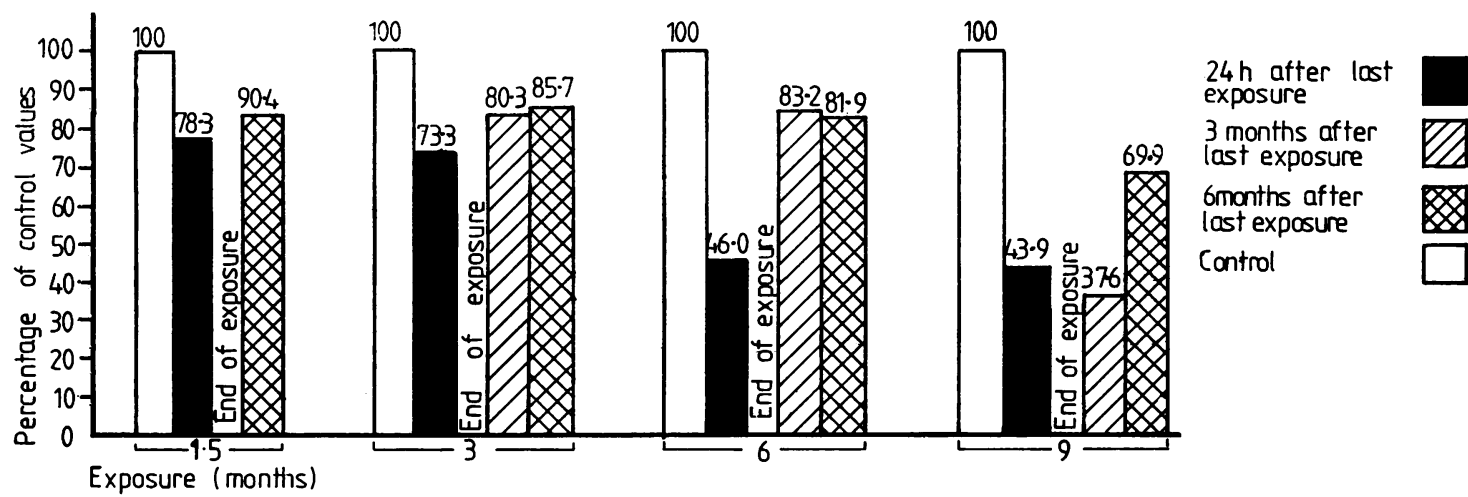

Fig. 4 Conduction velocity in the sciatic and tibial nerves of rats exposed to $1.6 \mathrm{mg} C \mathrm{~S}_{2} / \mathrm{l}$. The velocities are expressed as percentages of the control values.

Table 2 Conduction velocity in the sciatic and tibial nerves of rats exposed to $0.9 \mathrm{mg} C \mathrm{~S}_{2} / \mathrm{l}$ air

\begin{tabular}{|c|c|c|c|c|c|c|}
\hline \multirow{3}{*}{$\begin{array}{l}\text { Duration of } \\
\text { exposure } \\
\text { (months) }\end{array}$} & \multicolumn{6}{|c|}{ Conduction velocity in the sciatic and tibial nerves at various times after end of exposure } \\
\hline & \multicolumn{2}{|l|}{24 hours } & \multicolumn{2}{|l|}{3 months } & \multicolumn{2}{|l|}{6 months } \\
\hline & Control & $C S$ & Control & $C S_{2}$ & Control & $C S_{2}$ \\
\hline 3 & $51 \cdot 2 \underset{(8)}{ \pm} 6 \cdot 8$ & $45 \cdot 4 \underset{(8)}{ \pm} 6 \cdot 8$ & - & - & - & - \\
\hline 6 & $\begin{array}{c}51 \cdot 5 \pm 6.4 \\
\text { (11) }\end{array}$ & $\underset{(8)}{43 \cdot 0 \underset{(1)}{ \pm} 2 \cdot 2^{* *}}$ & $54 \cdot 3 \underset{(8)}{ \pm} 6 \cdot 5$ & $\begin{array}{c}43.8 \underset{(7)}{ \pm} 4.8 * \\
\text { (7) }\end{array}$ & $\begin{array}{c}46.8 \pm 5 \\
\text { (7) }\end{array}$ & $\begin{array}{c}39.6 \pm 3.9 * \\
\text { (7) }\end{array}$ \\
\hline 12 & $\begin{array}{c}50.7 \pm 6.0 \\
\text { (10) }\end{array}$ & $\begin{array}{c}39 \cdot 0 \underset{\text { (9) }}{ \pm 5 \cdot 1^{* * *}} \\
\text { (1) }\end{array}$ & $\begin{array}{c}47 \cdot 8 \pm 4 \cdot 7 \\
(9)\end{array}$ & $\begin{array}{c}32 \cdot 3 \pm 4 \cdot 3^{ \pm * * *} \\
\text { (6) }\end{array}$ & $\begin{array}{c}37 \cdot 8 \pm 3 \cdot 3 \\
(7)\end{array}$ & $\begin{array}{c}32.5 \pm 1.9 * * \\
\text { (5) }\end{array}$ \\
\hline
\end{tabular}

Results expressed as in Table 1

axon. The initial changes comprise axonal swellings accompanied by ultrastructural alterations such as accumulation and degeneration of axoplasmic organelles, followed by fibre fragmentation and breakdown; this leads to a considerable reduction in the number of myelin fibres, especially after pro- longed exposure to $\mathrm{CS}_{2}$. No signs of primary segmental demyelination have been found.

It seems reasonable to suppose that the electrophysiological changes are caused by injury to axonal fibres in the peripheral nerves. However, the electrophysiological changes appear to precede the develop- 


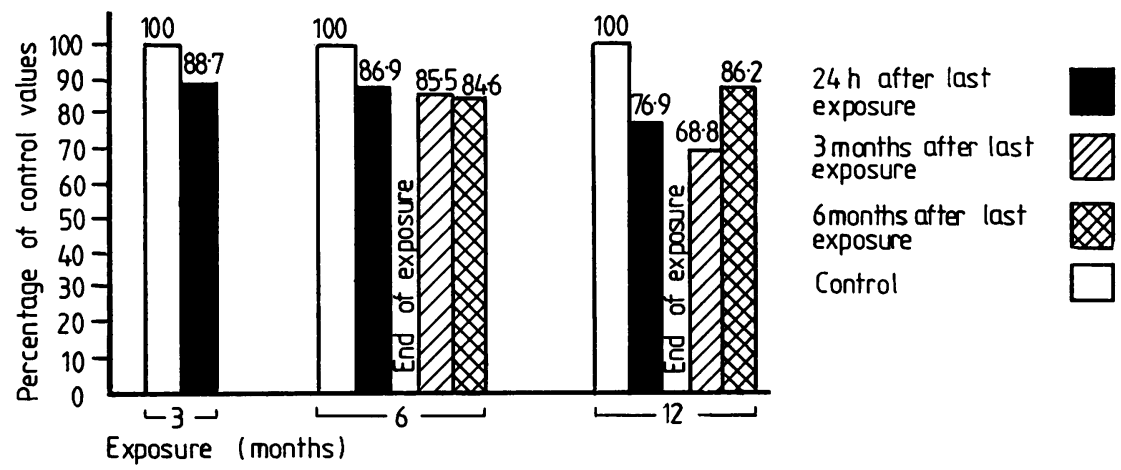

Fig. 5 Conduction velocity in the sciatic and tibial nerves of rats

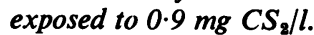
Velocities expressed as percentages of the control values. ment of obvious morphological changes, both in histological sections of major peripheral nerves, and in the ultrastructure of myelinated nervous fibres. A similar sequence of electrophysiological and morphological changes following chronic exposure of rabbits to $\mathrm{CS}_{2}$ has also been described (Linnoila et al., 1975).

These observations suggest that the recovery in conduction velocity observed after withdrawal of $\mathrm{CS}_{2}$ may be caused by the gradual regeneration of injured fibres in the peripheral nerves.

The importance of conduction velocity measurements in viscose workers has been emphasised (Seppalainen and Tolonen, 1974; Vasilescu, 1976). This technique enables neuropathy to be diagnosed at an early stage before the onset of obvious neurological symptoms. In addition, repeated measurements of conduction velocity are useful for prognosis in the neurological examination of a previously exposed subject. Lack of improvement in conduction velocity indicates irreversible neuropathy (Seppalainen and Tolonen, 1974). Persistent impairment of conduction velocity after protracted exposure to $\mathrm{CS}_{2}$ has also been confirmed in our present study.

In summary, the following conclusions can be drawn from the results of the experiments described here. First, reduction in conduction velocity is related to the level and duration of exposure to $\mathrm{CS}_{2}$ vapour. Second, a complete recovery of conduction velocity may follow a short intensive period of exposure to $\mathbf{C S}_{2}$. Finally, long-term exposure to $\mathrm{CS}_{2}$ may cause irreparable neuropathy and an irreversible reduction in the conduction velocity of peripheral nerves.
This study has been sponsored by the PolishAmerican Agreement No. 05-008-2 with Occupational Health Program, Public Health Service, Washington, USA.

\section{References}

Fullerton, P. H., and Barnes, J. M. (1966). Peripheral neuropathy in rats produced by acrylamide. British Journal of Industrial Medicine, 23, 210-221.

Linnoila, I., Haltia, M., Seppalainen, A. M., and Palo, J. (1975). Experimental carbon disulphide poisoning: morphological and neurophysiological studies. In Proceed ings of VIIth International Congress of Neuropathology, Akadémiai Kiado, Budapest, 1975, pp. 383-386. Edited by S. Környei, S. Tariska and O. Gosztonyi.

Lukas, E. (1969). Leitgeschwindigkeit peripherer Nerven bei Schwefelkohlenstoff ausgesetzten Personen. Internationale Zeitschrift für Klinische Pharmakologie Therapie und Toxicologie, 4, 354-358.

Lukas, E. (1970). Stimulation electromyography in experimental toxicology. La Medicina del lavoro, 61, 302-308.

Lukas, E., Kotas, P., and Obrusnik, I. (1974). Copper and zinc levels in peripheral nerve tissues of rats with experimental carbon disulphide neuropathy. British Journal of Industrial Medicine, 31, 288-291.

Seppalainen, A. M., and Tolonen, M. (1974). Neurotoxicity of long-term exposure to carbon disulphide in the viscose rayon industry. A neurophysiological study. WorkEnvironment-Health, 11, 145-153.

Szendzikowski, S., Stetkiewicz, J., Wrońska-Nofer, T., and Zdrajkowska, I. (1973). Structural aspects of experimental carbon disulphide neuropathy. I. Development of neurohistological changes in chronically intoxicated rats. Internationales Archiv für Arbeitsmedizin, 31, 135-149.

Szendzikowski, S., Stetkiewicz, J., Wrońska-Nofer, T., and Karasek, M. (1974). Pathomorphology of the experimental lesion of the peripheral nervous system in white rats chronically exposed to carbon disulphide. In Proceedings of the Symposium held in Kazimierz upon Vistula, Poland, May 18-20, 1972, pp. 319-326. Edited by I. HausmanowaPetrusewicz and H. Jedrzejowska. Polish Medical Publishers: Warsaw.

Vasilescu, C. (1976). Sensory and motor conduction in chronic carbon disulphide poisoning. European Neurology, 14, 447-457. 